\title{
"Subversivas": "Malas madres" y familias "desnaturalizadas"*
}

\author{
Sabina Amantze Regueiro**
}

\section{Resumen}

Este artículo analiza la perspectiva familiarista de la última dictadura militar argentina (1976-1983) sobre las militantes de organizaciones político-militares construidas como "malas madres/madres desnaturalizadas". Hundiendo sus raíces en las tradiciones del eugenismo, el higienismo y el catolicismo, las categorías de "abandono", "peligro" y "herencia" de la "subversión", se instrumentaron para justificar la "salvación" de sus hijos/as, y así de la sociedad, apropiándose criminalmente de los/as niños/as. De esta manera, el estudio de este caso paradigmático, pretende contribuir al campo de discusión en torno a la rica y compleja relación entre parentesco, género y política.

Palabras clave: Parentesco, Género, Política, Apropiación de niños/as.

\footnotetext{
* Recebido para publicação em 5 de dezembro de 2012, aceito em 25 de março de 2014.

** Instituto de Ciencias Antropológicas - Instituto Interdisciplinario de Estudios de Género, Facultad de Filosofía y Letras, Universidad de Buenos Aires, Argentina. Becaria postdoctoral CONICET. sabinaregueiro@hotmail.com
} 
424 "Subversivas": "Malas madres" y familias "desnaturalizadas

"Subversive", "Bad Mothers" and "Denatured"Families

\begin{abstract}
This article analyzes the familialist perspective of Argentina's last military dictatorship (1976-1983) on the militants of politicalmilitary organizations. These women were called "bad mothers/ mothers denatured". Sinking its roots in the traditions of eugenics, the hygienism and Catholicism, the categories of "abandonment", "danger" and "inheritance of subversion", were implemented to justify the "salvation" of their children and so the society, appropriating children criminally. Thus, the study of this paradigmatic case aims to contribute to the field of discussion about the rich and complex relationship amongst kinship, gender and politics.
\end{abstract}

Key Words: Kinship, Gender, Politics, Appropriation of children. 


\section{Introducción}

La apropiación de medio millar de niños/as hijos/as de detenidos/as-desaparecidos/as durante la última dictadura militar argentina (1976-1983) se ha instrumentado a través de una particular trama de relaciones de personas, grupos e instituciones sociales y políticas, en cuyo proceso se construyeron parentescos e identidades distintos a los de la familia de origen.

Dentro de esta variedad de actores, las burocracias estatales tuvieron un papel central, especialmente las FFAA y de Seguridad, a través de la implementación de determinadas prácticas, nociones y procedimientos que fueron empleados para consumar la desaparición de los niños/as. Estos organismos no pueden ser comprendidos por fuera de los valores sociales, ya que aún las regulaciones formales y las prácticas burocráticas cotidianas descansan fuertemente sobre los símbolos y el lenguaje de los lazos morales (Herzfeld, 1992).

En este artículo se analizará el discurso hegemónico familiarista neoconservador de la dictadura militar en sus nociones sociales claves para la comprensión de este proceso. Se indagará así en torno a diversas construcciones sobre la maternidad en particular y la familia en general en relación a las militantes políticas denominadas "subversivas".

A partir de una única - y pretendida natural - noción de maternidad de la cual estas militantes se apartaron por supuestas "desviaciones" morales, se buscó justificar la necesidad de "salvación" de estos/as niños/as y así de "salvación" de la sociedad (Villalta, 2012). Estas mujeres definidas como "terroristas" fueron consideradas "malas madres" que "abandonaban" a sus hijos/as y los ponían en "peligro". La finalidad de la apropiación era evitar la herencia de sus "males", la reproducción social de la "subversión" a través de una mala crianza, y los actos futuros de "venganza" de sus hijos/as.

Estas lecturas morales respecto de la maternidad pueden ser observados tanto en los discursos públicos transmitidos por los medios de comunicación, las reproducciones de los comunicados 
oficiales emitidos por las FFAA, como en las comunicaciones personales de miembros del gobierno militar a familiares de desaparecidos o a ex detenidos - desaparecidos declaradas en diversas causas judiciales.

A modo de hipótesis, podríamos reflexionar en torno a la influencia que en los argumentos familiaristas de la dictadura pudieron tener distintas tradiciones de pensamiento que nutrieron históricamente los debates públicos en torno a la maternidad en relación a los opositores políticos en la Argentina, como el eugenismo, el higienismo y el catolicismo.

De esta manera, en este artículo se ofrecen algunas claves para comprender cómo estos valores constriñeron, guiaron, influyeron las prácticas desplegadas por los agentes que formaron parte de la trama social que posibilitó la apropiación de los/as niños/as: las maternidades clandestinas donde nacieron durante el cautiverio de sus madres; la administración pública que permitió que fueran inscriptos falsamente como hijos/as de sus captores; $y$ los tribunales de menores, que autorizaron adopciones fraguadas, separando así a los/as niños/as de sus familias de origen.

\section{"Malas madres”, madres “desnaturalizadas"}

Gracias a los debates dados por el feminismo y la antropología, sabemos que las concepciones sobre la maternidad, la procreación y el parto son construcciones sociales que varían histórica y culturalmente y no están inscriptas en la naturaleza, sino en las relaciones sociales y de poder (Monreal Requena, 2000). Así, la maternidad implica no sólo una dimensión biológica del embarazo y alumbramiento, sino también "la tarea social, cultural, simbólica y ética de hacer posible la creación de un nuevo sujeto humano" (Tubert, 1996:10-11y 36).

Sin embargo, a pesar de que la maternidad (los modos de ser madre, las obligaciones y derechos en relación con los/as hijos/as, las pautas de crianza) es un constructo social y cultural que, como tal, varía según las sociedades y momentos históricos, en nuestras sociedades al menos desde el siglo XVIII, diferentes 
discursos y disciplinas han contribuido a delinear los trazos tradicionales de lo que implica "ser madre", "buena madre", "mala madre" o una madre "desnaturalizada".

Yvonne Knibiehler (2001) da cuenta del desarrollo de la "maternidad glorificada" que implicó la "invención de la buena madre" durante los siglos XVIII, XIX y principios del XX en Europa, específicamente en Francia. En los inicios de la secularización de la Ilustración la reforma paternalista y patriarcal se ve marcada por el determinismo biológico y el finalismo, donde el sexo femenino define la mujer moral. La maternidad, correspondiente a la "naturaleza" femenina, fue valorizada al estar al servicio del hijo. Así, por ejemplo, violar ciertos principios, como negarse al amamantamiento, mostraba que la mujer "traicionaba su naturaleza". Esto es así ya que el amor materno implicaba la consagración total de la madre a su hijo, lo que se convirtió en un valor de esta civilización y en un código de buena conducta.

Dado que el niño es a su vez el padre del futuro hombre, y que de los cuidados que recibía dependían la salud física y moral del adulto, el cuerpo de la mujer se convirtió en la matriz del cuerpo social. Jean-Jacques Rousseau, uno de los primeros representantes de esta perspectiva, encerraba a las mujeres en la función materna al servicio del hombre, sosteniendo que de la buena constitución de las madres dependía la primera educación, sus costumbres, pasiones y felicidad. Así también, si bien en los inicios de la Revolución Francesa (1789) las mujeres entraron en la acción política en tanto "madres de las generaciones futuras" encargadas de construir el porvenir, con la Convención (17921795), órgano a cargo del cual se hallaba el poder legislativo de la nueva República, la participación política femenina fue restringida y las militantes fueron consideradas "monstruos hembras" por algunos de sus miembros.

Estas representaciones en torno a la maternidad han gozado de gran popularidad en diversos contextos y dejaron sus rastros en representaciones contemporáneas, expresándose en distintos discursos públicos. Más allá de las resignificaciones históricas, también desde perspectivas recientes, las "malas madres" son 
aquellas mujeres que incumplen el ideal que implica ese papel social. Se convierten así en mujeres "desnaturalizadas", que contradicen la supuesta naturaleza femenina, de ser "buenas madres". Es por eso que serán estigmatizadas, diagnosticadas y penalizadas (Palomar Verea, 2004:17).

\section{Del eugenismo y el higienismo en Argentina}

Según Marcela Nari (2004), entre 1890 y 1940 el Estado argentino comienza a politizar la maternidad, es decir, la convierte en objeto de preocupación pública y política, al definir quién tiene derecho a ser madre, basándose en el derecho de la sociedad a reproducirse a sí misma. Y es aquí donde juega un papel la eugenesia como ciencia práctica, política. Los médicos eugenistas argentinos, influidos por el darwinismo social, se caracterizaron por el transformismo que implicaba la posibilidad de la modificación de individuos y de "razas" por la adquisición de caracteres del medio, y su transmisión por herencia. Por eso se proponía separar a los/as niños/as, mayores de 8 años, de sus madres indígenas para cortar la transmisión de la "cultura bárbara".

La eugenesia en el país fue fundamentalmente positiva, promoviendo la selección de los progenitores para el perfeccionamiento y construcción de la "raza", sustento del "ser nacional", de la argentinidad: no se trataba de una pureza étnica perdida sino de un crisol de "razas" cuya mezcla había que controlar. La "degeneración", o sea, la imperfección, incluía a ciertos opositores políticos, como los anarquistas. Sólo en estrechos círculos, como la criminología, cundió la eugenesia negativa que proponía impedir la reproducción de los seres inferiores para evitar el contagio, especialmente de aquellos considerados "irrecuperables" (Marcela Nari, 2004).

Este tipo de eugenesia se diferencia de aquella sostenida por los eugenistas alemanes, quienes durante el nazismo afirmaban que las diferencias entre los hombres tenían bases biológicas. A comienzo del siglo $\mathrm{XX}$, se redescubrieron las leyes de Mendel, 
extendiéndose sus simples mecanismos de transmisión hereditaria a la explicación de características complejas, como las cualidades intelectuales: un temperamento violento podría ser hereditario desde esta perspectiva. Estas concepciones son la base de la construcción de una civilización eugénica, que implementaba métodos de ingeniería genética, a través de una política demográfica de carácter biológico, orientada a evitar la destrucción de la cultura europea. La política de higiene racial, que incluía la creación de leyes y el funcionamiento de un tribunal eugénico que evaluaba el "prontuario" heredobiológico, debía impedir la proliferación de individuos de "razas" inferiores o personas consideradas deficientes de la propia sociedad. Para evitar su procreación se pasó de la esterilización al asesinato: la única salida era el exterminio. Las dolencias hereditarias a evitar eran variadas, desde la ceguera, a la depresión y el alcoholismo. Pero también eran considerados indeseables y "peligrosos" los comunistas, los opositores al nazismo, los homosexuales, los criminales y los "asociales" o "socialmente inadaptados" (Beiguelman, 1990).

Si bien el higienismo y el eugenismo se expandieron en Argentina fundamentalmente a fines del siglo XIX y principios del siguiente, mantuvieron su vigencia mucho tiempo más entre los médicos y los miembros de las FFAA y Seguridad. En términos de Jorge Salessi (1995) "la retórica higienista siguió siendo utilizada por las fuerzas represivas de la policía y el Ejército argentino durante el siglo veinte" y se dio una apropiación de los discursos y dispositivos de los médicos higienistas por parte de la criminología desde fines del siglo XIX. Ésta estuvo orientada fundamentalmente a la vigilancia de los inmigrantes europeos, miembros del movimiento obrero, especialmente socialistas y anarquistas. La criminalidad era pensada como una "enfermedad psicológica y moral que amenazaba la salud social". Muchos de estos médicos higienistas colaboraron en la modernización de la policía y del Ejército y se incorporaron a los "dispositivos más represivos de la burocracia estatal”, ya que será la policía la encargada de cuidar de la higiene social. Se atacaría "de lleno el foco de infección 
moral de donde brotan esos gérmenes virulentos, se destruiría la parte temible que está destinada a producir los crímenes políticos", de la llamada "delincuencia política". El objetivo era "preservar la raza humana de todas las causas de la degeneración física y moral", evitando el "contagio", la transmisión intergeneracional del "mal social" (Salessi, 1995:120-128). Tal como se expresa en una publicación higienista:

Lo que hoy constituye un vicio o un mal limitado a un grupo de individuos, se habrá convertido mañana, mediante la imitación o la sugestión en un mal social, y lo que era antes una causa de degeneración simplemente individual, se transformará a través de varias generaciones, en una causa de degeneración de la raza, si la educación y previsión higiénica no intervienen para evitarlo (Salessi, 1995:126, las negritas son mias).

El pacto médico - militar existente durante la última dictadura militar argentina retomó la metáfora de la infección y se movió frente a la apropiación de los hijos de los desaparecidos entre los términos de degeneración y la regeneración (Amado y Domínguez, 2004). Esta interpretación retoma el texto de la prestigiosa María Moreno (1994:126) quien afirma que a través de esta alianza, los militares en "el rapto de niños parecían conservar mitos de referencia del ochenta: si la degeneración puede ser adquirida, la regeneración también".

No debemos pensar sin embargo que el vínculo entre los discursos higienistas y eugenistas con los argumentos familiaristas de la dictadura, es simple y directo, sino producto de complejas mediaciones, cuyo análisis excede en mucho los objetivos de este artículo. Esta asociación entre tradiciones de pensamiento es apenas una hipótesis histórica, un juego de sentidos sugerente, una invitación a un abordaje sistemático que contribuya, eventualmente, a su fortalecimiento. 


\section{La familia "desnaturalizada" de la "subversión"}

El apropiador de una niña, hija de detenidos-desaparecidos, hombre del Servicio de Inteligencia del Estado durante la dictadura, dirigió una serie de cartas a la abuela biológica de la pequeña en el año 1985, como respuesta a ciertas declaraciones públicas realizadas por la mujer, en el marco de la difusión en los medios de comunicación de la causa judicial por ella iniciada para restituir a su nieta. También serían enviadas copias al diario El Día de Montevideo, al presidente uruguayo en funciones y a "todas las fuerzas vivas del Uruguay", país donde residía la abuela. Las misivas están escritas a máquina y llevan la firma manuscrita de la niña de 9 años, que según lo dicho "lee sobre la gente como ella", refiriéndose a la abuela. Estos documentos contienen un extenso desarrollo orientado a dar cuenta de las supuestas diferencias entre la niña y la mujer, en distintos aspectos considerados centrales por su apropiador: la política, la religión, la educación y la familia.

B) Respecto de la FAMILIA:

\section{Según Ud.:}

(1) la familia burguesa es fruto del sistema capitalista, consisten en la propiedad privada de la mujer por el hombre y se construye a expensas de la familia proletaria.

(2) El amor libre debe rechazarse por sus consecuencias sociales.

(3) El verdadero matrimonio, inspirado en el amor, y sin preponderancia masculina, debe ser monogámico y disoluble.

(4) La educación de los niños debe estar a cargo de la sociedad

(5) La familia debe quedar subordinada a la vida social y puede modificarse si las condiciones sociales así lo aconsejan.

\section{Le respondo YO (Daniela Romina FURCI)}

La FAMILIA es una institución natural que se origina y se basa en el matrimonio, monogámico, indisoluble. Su fin primordial es la transmisión de la vida y la educación de los hijos.

La FAMILIA comprende la sociedad conyugal, que une a los esposos, y la sociedad paternal, que une a los padres y a los hijos. El padre es el jefe natural de la FAMILIA. La madre se encuentra 
asociada a esta autoridad. A ella le corresponde ejercerla en ausencia del padre. El régimen de divorcio se opone directamente a la concepción auténtica de FAMILIA.

El niño tiene derecho a la formación física, intelectual, moral y religiosa. El derecho y deber de procurárselas compete a los padres.

(Salaberry, 1993:150, las negritas son mias).

En este fragmento textual pueden observarse dos concepciones de familia desde la perspectiva de este agente de Inteligencia. La primera parte de la carta, encabezada por el título "Según usted", describe aquella perspectiva que tendría la abuela de la criatura, que podría corresponderse en realidad a las concepciones sostenidas por las organizaciones político-militares revolucionarias a las que pertenecían el padre y la madre desaparecidos de la criatura. ${ }^{1}$ La segunda parte, desarrollada bajo el nombre falso de la niña, "Daniela Romina Furci", corresponde en cambio a la mirada de su apropiador.

La niña, quien se proclamaba falsamente como la autora de la misiva, aparece en el texto como una ferviente católica, a diferencia de su abuela que se supone atea. El texto está plagado de citas bíblicas admonitorias, llamando a la mujer "arpía" de acuerdo a la definición de ese texto sagrado.

Relata la cotidianeidad de su hogar, la madre lavando y cocinando, las llamadas diarias de sus supuestas abuelas, las largas escenas de expresión de cariño con sus "padres", en fin, la rutina de la niña, quien ante las directivas de sus mayores manifestaba sumisamente (y en un tono un tanto formal, por no decir policial): "yo a todo respondo en forma afirmativa" (Salaberry, 1993:142).

Desarrolla además su concepción negativa sobre un sistema educativo que "aleja a los niños de la influencia de sus padres", ejerciendo control sobre ellos (Salaberry, 1993:143). Esto se articula directamente con la formación política, reforzando la contraposición con la vida familiar

[mis familiares] no me imaginan usando uniforme y recibir [sic] instrucción militar aceptando las enseñanzas y

1 Para un desarrollo sobre las concepciones familiares de una de las principales organizaciones político-militares revolucionarias véase Oberti (2004). 
doctrinas de algún partido, como ud. les habrá inculcado a sus hijos. Esto se lo digo por simple deducción... si no explíqueme qué hacían en mi país [Argentina] su hija y su yerno en vez de estar en el Uruguay, unidos todos en el seno familiar, ¿quiénes eran?... ¿̇guerrilleros? (Salaberry, 1993:142, las negritas son mias).

Afirma también que la mujer que según él se autodenomina su abuela es un "agente de propaganda", miembro de una "cripto organización filo-comunista": Abuelas de Plaza de Mayo. Su objetivo es desestabilizar la incipiente democracia argentina, a través de su injerencia extranjera, ya que recibe órdenes del "frente internacional".

Coronará finalmente este desarrollo con una fuerte afirmación, cuando la niña aún no se había realizado el análisis genético que determinaría su filiación:

ya ve Ud. cómo se van estableciendo "algunas" diferencias entre Ud. Y YO, entre su "herencia" de pensamiento y MI HERENCIA congénita (Salaberry, 1993:152).

En suma, en su concepción sobre "la ética", se opone por un lado, la familia unida bajo la autoridad paterna sobre los hijos, la mujer en el hogar, lo natural, lo auténtico, lo verdadero, el bien, Dios, la Nación. Por el otro, predomina la vida política y social por sobre lo familiar, el partido, la guerrilla, el comunismo, el ateísmo, lo internacional, la transformación. Cabe destacar la responsabilización que hace recaer sobre la mujer por inculcarle la doctrina partidaria que llevó a su hija, a la madre de la niña, a alejarse de su hogar en Uruguay para ir a la Argentina, donde desapareció con su esposo.

Estas afirmaciones pueden ubicarse en el contexto más general de las concepciones en torno a las familias sostenidas por las voces hegemónicas del terrorismo de Estado. Siguiendo a Estela Grassi (1993) el neoconservadurismo de la dictadura militar sostuvo que la crisis social que se vivía era una crisis moral, por lo que debía leerse en términos de valores considerados 
suprasociales: Patria, Familia y Religión. Esto implicó la despolitización de los problemas socioeconómicos y una naturalización del orden social. Así, el discurso familiarista que se torna hegemónico en los '70 se basa en la familia como entidad ahistórica, abstracta, natural y sagrada.

De acuerdo con Grassi (1993), la recuperación estratégica del reconocimiento social de la autoridad tradicional se tradujo en la responsabilización privada de la familia en la reproducción ideológica y control de sus miembros, lo que permitió la culpabilización de la familia por la desaparición de sus miembros. La familia aparecía así como la responsable de la formación, física, intelectual, moral y religiosa de los hijos, en la cual los padres debían ser el modelo de conducta. Es por eso que los males del niño eran considerados principalmente producto de la familia (Filc, 1997).

Consideramos que el niño es la consecuencia de la familia... los males de un niño son, en un 90 por ciento, consecuencia de una mala familia (Ministro de Bienestar Social, contraalmirante Jorge Fraga, en entrevista al diario La Nación) (Filc, 1997).

"Los discursos 'científicos' de la psicología, la psicopatología, la pediatría y otros han colaborado en estas construcciones discursivas al atribuir a las madres las causas de los problemas de la salud mental y física de los hijos" (Palomar Verea, 2004:24). Es elocuente en este sentido el testimonio de una sobreviviente de un Centro Clandestino de Detención, según el cual uno de los represores le dijo cuando estaba detenida desaparecida, que sus hijos estaban en otra dependencia militar y que "el psicólogo había diagnosticado no entregarlos a la familia por estar muy politizados". Los niños habían sido secuestrados por el Ejército a fin de ser usados como anzuelo para secuestrar también a su padre. ${ }^{2}$

2 Testimonio de A. M. M ante CONADEP (Comisión Nacional sobre la Desaparición de Personas). 
Esto puede entenderse en términos de "ortopedia social", en tanto forma de poder de la sociedad disciplinaria, de control social sobre la peligrosidad virtual de los individuos. La vigilancia (la policía) y la corrección (el saber médico y las ciencias humanas) implican una forma de saber basada en el examen, que determina si la conducta es normal, correcta o no (Foucault, 2003). ${ }^{3}$

Ahora bien, la familia desde esta perspectiva tradicional es "natural", los lazos de sangre tornan naturales los roles jerárquicos, hereditarios los valores familiares e indisoluble su unidad. Como la familia es la "célula básica de la nación", la sociedad tiene entonces un origen biológico y la identidad nacional, el ser argentino, es producto de una combinación de sangre y espíritu heredados. Esta mirada emparentada con concepciones catolicistas, resulta en otra dimensión de la naturalización de la política y la cultura. ${ }^{4}$

Desde esta concepción ideológica, la familia debía ser "salvada" y protegida de la infiltración "subversiva", considerada como la enfermedad moral que causa su "desnaturalización" y así su destrucción (Filc, 1997). Dado que la dinámica interna de la familia se consideraba articulada con el conjunto sociedad, la

3 Bernardo Beiguelman (1990) sostiene que durante el nazismo los antropólogos con formación médica, debían identificar a los "seres inferiores" no alemanes (judíos, negros, gitanos, eslavos) y los psiquiatras, a los "seres inferiores" alemanes (psicópatas, deficientes, homosexuales, epilépticos).

${ }^{4}$ Este argumento se encuentra ya en los debates en torno a la familia que se integran a los enfrentamientos político - culturales entre el peronismo y la Iglesia al ampliarse la potestad del Estado para intervenir en el orden familiar. La Iglesia afirmaba que la familia era anterior al Estado, y que en ella se asentaba el orden natural y cristiano de la sociedad. El lazo biológico estaba presente en las reivindicaciones peronistas más progresistas - que rompían con un discurso en sus orígenes tan familiarista como el de fines de los años '30 - a favor de la disolución del estigma de los hijos ilegítimos y se oponían al conservadurismo católico que sobreponía la legalidad del matrimonio por encima del lazo biológico (Cosse, 2006). Durante la dictadura, en cambio, se privilegió la ideología política familiar a la hora de evaluar a las familias, coincidiendo Iglesia y poder político en este sentido. 
destrucción de la estabilidad de la familia patriarcal, conllevaba la destrucción de la sociedad.

Ese discurso se hallaba en la base del dispositivo de control de las familias a través de la intervención del Estado como garante del orden, obligado a actuar por la amenaza de la "subversión" (Grassi, 1993). La división de la familia producía la división nacional, así que como el patriarca en la familia, el Estado debía ejercer su autoridad para que se extrajeran los "tejidos infectados" y se "restaurara la paz" y los valores argentinos de la esencia del "ser nacional": "Dios, Patria y Hogar" (Filc, 1997).

La metáfora de la "subversión" como enfermedad y de la nación como familia (Filc, 1997) justificaba la intervención del Estado en las familias, el control público de "lo privado" incluido el ejercicio de la maternidad, con justificaciones "salvacionistas" leídas en clave moral (Fonseca, 2006) y no política.

¿Cómo se conciliaba la exaltación, la sacralización de la familia con la destrucción de miles de familias concretas? La familia "subversiva" estaba "desnaturalizada", ya que los/as "subversivos/as" eran considerados "malos padres" y "malas madres" que no cumplían con las reglas naturales de la paternidad / maternidad y contagiarían a sus hijos/as. Por eso los/as niños/as debían ser criados por "buenos padres" para ser "verdaderos argentinos".

¿Cómo se conciliaban estas concepciones en torno al parentesco natural con el parentesco construido de la apropiación? Es la conducta lo que determina la pertenencia de los padres a la nación y es la crianza, o sea el moldeado de la conducta, la que la determina en el caso de los hijos, pero no la sangre (Filc, 1997). Estas concepciones parecerían evocar las ideas transformistas del eugenismo, que combinaban ambas dimensiones, la biológica y la cultural, atravesadas fuertemente por la política, si bien sabemos que la combinación de estos dos elementos trascienden estas perspectivas ideológicas y se hallan en distintas construcciones en torno al parentesco, yendo así más allá de este caso específico. 


\section{Del "abandono" y el "peligro"}

El arquetipo del "subversivo", en masculino genérico, era el enemigo extranjero, apátrida, comunista, no sinceramente religioso, sin pautas morales. El guerrillero no valoraba la familia, abandonaba a sus hijos y tenía parejas inestables. Las mujeres eran "malas madres", malas amas de casa, malas esposas (Calveiro, 1995) porque desconocían su esencia femenina al volcarse a la actividad político-militar en vez de quedarse en su casa (Álvarez, 2000). Puede observarse que dentro de la categoría de "subversivo", se asocia la militancia directamente a la participación en la guerrilla, a la lucha armada, y la "guerra" o lo guerrero se vincula con lo masculino. Violar la "esencia" femenina es lo que puede remitir a la idea de "desnaturalización", de contradicción de una naturaleza en las "malas madres".

Estas concepciones se reflejaron en algunos artículos periodísticos de la época. Especialmente interesantes son las notas de los diarios, donde se suelen citar textualmente los comunicados de los comandos de las distintas zonas militares.

En los dos primeros fragmentos seleccionados puede apreciarse cómo se narra la forma en la que los "delincuentes subversivos" utilizaban niños/as como "escudos" humanos.

El joven emprendió la fuga cubriéndose con disparos de un arma de fuego y al mismo tiempo que intentó arrebatar a una niña de corta edad de los brazos de su padre que circunstancialmente se encontraba en el lugar. Iniciada la persecución para repeler la agresión, fue abatido. Pudo constatarse que se trataba de un delincuente subversivo. ${ }^{5}$ [Las negritas son mías]

Dos criaturas, una de un año y medio y otra de tres meses aproximadamente, fueron utilizadas como escudo por la delincuente subversiva cuando intentó refugiarse de las fuerzas legales (...) cabe señalar que las dos criaturas fueron

5 Diario La Opinión, 22/01/1977, "Otros cuatro extremistas fueron abatidos". 
rescatadas ilesas y se encuentran bajo control y cuidado de una institución especializada. ${ }^{6}$ [Las negritas son mías]

En el siguiente fragmento se hace referencia a la manera en la que la madre de una niña, la deja "abandonada" luego de un allanamiento.

Finalizada la operación se encontró abandonada en el lugar una criatura de unos 4 años, cuya madre al parecer había fugado aprovechando la confusión producida durante el enfrentamiento. ${ }^{7}$ [Las negritas son mías]

Del cruce de este documento con otras fuentes, puede desarmarse la construcción del relato. El hombre calificado como "extremista" era el padre de la niña y fue efectivamente asesinado en el lugar. Su madre, herida, fue secuestrada y mantenida detenida - desaparecida en un Centro Clandestino de Detención, tal como señalan distintos testimonios. La mujer se hallaba embarazada y dio a luz a una niña en esa guarnición militar, la cual fue posteriormente apropiada por un oficial de Inteligencia. $\mathrm{Su}$ hija mayor mencionada en este artículo fue entregada a sus abuelos. Es decir, el supuesto "abandono" no fue más que la separación de la niña de sus padres a raíz de su secuestro y asesinato.

La madre de la joven embarazada secuestrada impugnó la validez de esta narrativa que presentaba a su hija como una "mala madre" en un habeas corpus presentado para denunciar su desaparición. En este documento hizo alusión al comunicado del Comando en jefe del Ejército publicado en el diario, donde se decía que su hija había huido "abandonando" a la niña, manifestando que ella descartaba esa versión. Afirmó que si la joven hubiera estado en libertad se hubiera puesto en contacto con ellos, para saber sobre la suerte corrida por su hija. En este

${ }^{6}$ Diario La Opinión, 21/01/1977, "Confirman que fueron abatidos cuatro cabecillas subversivos".

7 Diario La Nación, 13/01/1977, "En un enfrentamiento murió un extremista". 
sentido aseguró: "conozco su temperamento y su dignidad de madre", argumentando además que su hija no habría usado armas y sugiriendo que se hallaba herida.

\begin{abstract}
Mi nieta - quien se encuentra gravemente afectada en lo psíquico - manifiesta en su media lengua y en palabras casi incoherentes que 'cuando reventaban globos, mamita estaba en la cama enferma y lloraba por lo que supone que su hija no participó del enfrentamiento.
\end{abstract}

Otro caso nos permitirá analizar con mayor profundidad los usos de estas nociones de maternidad y paternidad de los/as "subversivos/as". Se trata de una serie de notas editoriales publicadas en una popular revista de la época orientada fundamentalmente a una audiencia femenina, realizadas en torno al secuestro de una pareja que tenía una niña pequeña, quien fue entregada a sus abuelos tras el operativo. Sin embargo, antes de esto, la criatura fue fotografiada y sin consentimiento alguno de sus familiares, fue la protagonista de un relato donde se ofreció una versión extrema del "abandono": su orfandad fue producto del desamor hacia ella de sus padres "terroristas".

Alejandra es huérfana. Y de una manera especial, a una edad especial. Porque tiene apenas 4 años. Y porque sus padres eran terroristas argentinos muertos en Montevideo mientras planeaban nuevas acciones delictivas: su padre murió en un choque con fuerzas uruguayas, la madre se suicidó con cianuro a la vista de su hija. Ahora Alejandra está sola para siempre. Sin casa, sin padre, sin madre, sin infancia posible, sin familia, sin recuerdos gratos, sin nada. Alejandra es huérfana. Sus padres decidieron que lo fuera. No pudo ser para ellos un hecho totalmente imprevisto la posibilidad de su propia muerte. No pudo tampoco serles desconocido el hecho de que otros subversivos salvaron su vida rectificando el camino y entregándose a las autoridades. No. Ellos prefirieron "vivir peligrosamente". Y así murieron. La muerte llega algún día para todos. Pero quien ama no quiere morir. Quiere vivir para ese amor. 
Quiere vivir para su pareja, para sus hijos, para su familia, para su país. Solamente de ese amor de quienes quieren vivir se puede esperar algo. Querer morir no es sólo cobardía. También es desamor. Y ese desamor es lo único que le ha quedado a Alejandra. Eso, y su muñeca de trapo. ${ }^{8}$ [Las negritas son mías]

Puede pensarse, a modo de hipótesis, que estas narrativas que aluden a hechos falsos o que tienen una interpretación tendenciosa, fueron armadas en pos de demonizar a los militantes políticos para legitimar su asesinato. Implícitamente, el reforzamiento de esta imagen de "malas madres" y "malos padres" ofrecería una justificación para las apropiaciones que ocurrían en muchos otros casos, aunque no fueran reconocidas públicamente.

Existieron además otros recursos interpretativos recurrentes empleados para justificar la apropiación de los/las niños/as, no ya tácitamente, sino expresamente.

\section{De la "venganza" y la educación para la "subversión"}

Una las razones que justificaban la apropiación de los/as hijos/as de los/as detenidos/as - desaparecido/as aducidas explícitamente por miembros de la dictadura militar era de orden "preventivo": el "odio" y la posibilidad de "venganza" aparecían como fantasmas políticos.

Según declaraciones de un padre que buscaba a su hija desaparecida, el subjefe del Estado Mayor del Ejército en 1978 le expresó abiertamente: "un problema que tenemos que enfrentar es el de los hijos de los subversivos para evitar que se críen con odio hacia las instituciones militares" 9 .

\footnotetext{
8 Revista Para Ti, diciembre de 1978, "A ellos no les importaba Alejandra".

9 V. J. R y otros s/presunta infracción a los arts. 146, 293 y 293 CP, 1998. De aquí en más, se indicará el nombre abreviado de la causa judicial y el año al que corresponde al extracto presentado.
} 
También declaró que supo, a través de un experto en la comisión de derechos humanos de las Naciones Unidas, que un coronel auditor, secretario legal y técnico de la presidencia, le dijo:

Se ha aprobado a nivel de la Junta Militar una doctrina mediante la cual los hijos de los subversivos no deben ser educados con odio hacia las instituciones militares... que por eso entregaban a los chicos en adopción. ${ }^{10}$ [Las negritas son mías]

Resulta interesante recuperar las palabras de uno de los principales dirigentes del genocidio nazi, dado que aparece en su discurso esta misma preocupación.

En 1943, Himmler exhortó a los hombres de las SS en un discurso: "Llegamos a la pregunta: ¿Qué pasa con las mujeres y los niños? He decidido encontrar una solución clara también a este respecto. En realidad no me creo justificado a exterminar a los varones, ya sea matándolos o mandando que los maten, y dejar que crezcan vengadores en potencia en forma de niños" (Bock, 1996:432, las negritas son mias).

En este contexto puede apreciarse que "las judías morían como mujeres, como madres y progenitoras de la siguiente generación de judíos", potenciales "vengadores" de los asesinos de sus padres: la mayoría de los niños eran asesinados (Bock, 1996).

Una sobreviviente de un Centro Clandestino de Detención afirmó que suponía que como uno de los niños nacidos en cautiverio, hijo de una detenida - desaparecida, tenía origen judío los marinos no lo quisieron y por eso lo entregaron a su familia (Actis et alii, 2001). Esta explicación fue elaborada para explicar un hecho por demás excepcional, ya que la inmensa mayoría de los recién nacidos en las maternidades clandestinas durante el cautiverio de sus madres fueron apropiados. La interpretación se

${ }^{10}$ V. J. R y otros s/presunta infracción a los arts. 146, 293 y 293 CP, 1998. 
nutre también de una gran cantidad de testimonios que dan fe del fuerte antisemitismo reinante entre los represores. Sin embargo, puede afirmarse ciertamente que hubo muchos/as niños/as de origen judío que sí fueron apropiados/as, tanto en el caso de la ESMA como de otros $\mathrm{CCD}$, por lo que esta hipótesis no se sostendría, y las razones por las que se actuó en forma diferente con este niño en particular continúan siendo una incógnita. Nuevamente, prima, aún en el caso de niño/as de origen semita, la cultura sobre la biología.

Así, como hemos anticipado en el apartado anterior, en el caso argentino el acento está puesto en la cultura, en el aprendizaje, en la crianza. Esto justamente es lo que se buscaba modificar, y por eso la mención de la necesidad de la entrega en "adopción" de los niños. El "mal" no lo llevan las criaturas en la sangre, puede ser transformado a partir del ambiente: esta acción estaría en los fundamentos de la apropiación.

En esta misma línea, según la declaración de un testigo, el subjefe de la maternidad clandestina de un Centro Clandestino de Detención en la cual las detenidas - desaparecidas daban a luz en cautiverio a sus hijos que eran posteriormente apropiados, un teniente, segundo jefe militar de Obstetricia, "tenía la pretensión de mejorar la raza". Estaba vinculado a la "lucha por la subversión" y al menos en una oportunidad realizó una cesárea a una secuestrada. ${ }^{11}$ En el sentido antes expuesto, estas afirmaciones pueden pensarse en términos de una concepción social de "raza". ${ }^{12}$

Asimismo, el ex jefe de la Policía de la provincia de Buenos Aires, coronel y luego general de la Jefatura y de la Dirección

\footnotetext{
11 Testimonio de C. R. ante CONADEP.

12 Otro ejemplo de la utilización de la categoría de "raza" en términos políticos se vio en el testimonio de una sobreviviente quien escuchó que decían en referencia a la hermana del líder de una importante organización político - militar revolucionaria, el PRT-ERP, que se hallaba allí secuestrada: "Hay que terminar con toda su raza", haciendo alusión a que la matarían a ella y a otro de sus hermanos.
} 
General de Investigaciones, manifestó a su vez que los niños eran entregados a "organismos de beneficencia" y no "eliminados":

Personalmente no eliminé a ningún niño; lo que hice fue entregarlos a organismos de beneficencia para que encontraran nuevos padres. Los padres subversivos educan a sus hijos para la subversión. Eso hay que impedirlo... (Nosiglia, 1985:16-17, las negritas son mias).

Esta interpretación es recogida también por Donna Guy (2008) al manifestar que el asesinato de los padres era un esfuerzo por prevenir el nacimiento de una progenie futura potencialmente defectuosa. "Buenos" padres serían elegidos para reemplazar a aquellos designados como enemigos del Estado, ya que los militares temían que los hijos de guerrilleros sospechosos se volvieran ellos mismos guerrilleros si no los ubicaban en otras familias.

Un teniente de fragata cuya hija y nieta habían desaparecido, declaró que cuando se entrevistó con el general a cargo del Comando de Institutos Militares, éste admitió que "esas normas eran para evitar que los hijos de los 'zurdos' caigan sino en hogares bien constituidos ideológicamente, colocarlos en familias bien constituidas con el único fin de enderezarlos". ${ }^{13}$

De esta manera, la apropiación de los niños que en el corto plazo puede verse como la expresión de una concepción particular de los/as hijos/as de detenidos/as - desaparecidos/as en tanto "botín de guerra", podría pensarse en el largo plazo como una forma de controlar la descendencia del enemigo, evitando la formación de nuevos adversarios políticos en el futuro.

Así como la dictadura buscó modos específicos de atacar y humillar a la mujer por ser mujer, también encontró una forma específica de hacerlo con las generaciones futuras: la apropiación de los hijos. El efecto inmediato fue conservar a las criaturas como parte del botín de guerra. Pero a futuro

${ }^{13}$ V. J. R y otros s/presunta infracción a los arts. 146, 293 y 293 CP, 1998. 
444 "Subversivas": "Malas madres" y familias "desnaturalizadas

significa: "nos quedamos con vuestra siembra y la controlamos de ahora en adelante" (Alvarez, 2000, las negritas son mias).

Es interesante ver cómo las representaciones en torno a la apropiación con vistas a evitar la continuidad del accionar de militantes de generaciones futuras, se recrearon años después. Estas concepciones se plasmaron claramente en un editorial publicado en un diario a raíz de un conflicto desatado por la restitución de una niña en el año 1990.

Todos recordamos la película "Los niños del Brasil" en la que, desde su selvático escondite, el doctor Joseph Menguele [sic] había reproducido artificialmente las circunstancias genéticas y familiares que dieron origen a Adolfo Hitler.

Los setenta y dos niños del Brasil eran réplicas exactas de Hitler en cuanto a su genética y personalidad, surgida esta última de la convivencia con padres sustitutos de las mismas características en cuanto a edad, carácter y profesión que los del "Führer".

Menguele perseguía el objetivo de crear setenta y dos líderes que llevarían a la raza aria a la preponderancia mundial.

De las selvas brasileñas a las orillas del río de La Plata la fantasía hollywoodense cobra realidad.

Los denominados "niños restituidos" son nuestra versión de "los niños del Brasil", llamado a liderar la causa que sus padres dejaron trunca. Sus antecedentes genéticos, gentilmente "recauchutados" por el Banco Nacional de Datos Genéticos, les dan las credenciales para completar su formación en el ambiente de las "Abuelas de Plaza de Mayo" que tantas flores nos proveyó en décadas pasadas. [...]

El verdadero objetivo de la "restitución" [...] probablemente se conozca cuando todos esos niños sean mayores de edad.

Los niños "restituidos" están siendo entrenados como líderes en lo que será la futura agrupación "Hijos de Plaza 
de Mayo", órgano de referencia para las futuras generaciones de izquierda ${ }^{14}$ [las negritas son mías].

En el artículo aquí presentado es interesante ver cómo el nazismo ofreció metáforas para hablar del "mal radical" (Vezzetti, 2009:160) también para aquellos que defendían la dictadura, desplegando una interesa inversión argumental. Este "mal", representado en esta nota por Adolph Hitler, estaría encarnado en los padres desaparecidos de los niños restituidos, y el Dr. Josef Mengele (sic) en Abuelas de Plaza de Mayo. Ellas serían las encargadas de sustituir a sus padres subversivos y de producir las "réplicas" en sus hijos recuperados, a partir de la identificación genética y de la crianza familiar, pero sobre todo, de su formación en el "ambiente" de Abuelas.

De esta manera se afirma que las restituciones de los niños llevadas a cabo por Abuelas tienen como verdadero objetivo entrenarlos como líderes para la creación de una agrupación política de izquierda que se llamaría "Hijos de Plaza de Mayo" que recuperaría el proyecto político de sus padres y madres desaparecidos/as, trascendiendo de esta manera la mera intención de "venganza". Cabe destacar que cinco años después se fundaría la organización HIJOS (Hijos por la identidad y la justicia, contra el olvido y el silencio), aunque su composición no se redujo a los/as jóvenes restituidos/as sino que ha incluido a otros/as hijos de detenidos/as - desaparecidos/as (e incluso, más tarde, a jóvenes que no lo son).

Este fragmento nos permite mostrar la complejidad $y$ diversidad de las representaciones sociales, sus fisuras $y$ ambigüedades, donde pueden combinarse concepciones racistas $y$ culturalistas, así como ha ocurrido históricamente en el higienismo y eugenismo latinoamericano en distintos contextos. ${ }^{15}$ Esta

\footnotetext{
${ }^{14}$ Diario La Prensa, 11/05/1990, "Los niños del Brasil", por Celia PalomasAlarcón.

${ }^{15}$ Véase: Mariza Correa. As ilusões da liberdade. A escola de Nina Rodrigues y la Antropologia no Brasil. Sao Paulo, Edusp, 1998; Jurandir Freire Costa. História da Psiquiatria no Brasil. Garamond, 2009 [1976]; Nancy Stepan, The hour of
} 
variedad y mixtura de concepciones sobre la herencia se observan también en casos particulares, como en el caso de una mujer que inscribió como hija propia a una niña secuestrada tras su nacimiento durante el cautiverio de su madre - o sea que no fue por ella criada - y ante un berrinche le gritó "iHija de guerrillera tenías que ser para ser tan rebelde!" (Juicio oral y público, Tribunal Oral Federal n. 5, Capital Federal, 2008).16

\section{De la "salvación"}

En su reflexión sobre las prácticas y expedientes vinculados a la gestión de "minoridades", estudiados a través de procesos de guarda y adopción en Brasil, Vianna (2002) analiza relatos sobre situaciones de niños desnutridos, enfermos, cedidos en las calles, dejados con vecinos, recogidos en los trenes o en las puertas de las iglesias, usualmente a partir de diversos problemas atravesados por sus padres. Para dar cuenta de lo que llamará "escena de salvación", la autora cita la denominada "bondad de los extraños" de John Boswell (1988) que alude a las imágenes de "rescate" que construyen una representación moral positiva para los que reciben a los niños: los "salvadores". En ellos confluye el deseo de "cuidar" y la urgente necesidad de "rescatar". Sin ellos el "futuro", el "destino" de estos niños habría sido por lo menos, incierto. La autora afirma que estos relatos de "rescate" y "salvación" forman parte de un diseño predeterminado en el que tanto las posiciones de los actores como la relación moral entre ellos están ritualmente determinadas, invocando lo mítico: "abandono", “peligro" de muerte, "rescate", la nueva vida...

Por otro lado, Pilar Calveiro (1995) ha considerado que la preservación de la vida de los niños sería producto de ciertos

eugenics. Race, Gender and Nation in Latin America. Ithaca, Cornell University Press, 1996), entre otros.

${ }^{16}$ Regueiro (2010). En este artículo se destaca fundamentalmente el uso de los valores primordiales como "la familia" por parte de los familiares de desaparecidos en tanto activistas políticos. Para este tema véase también Sanjurjo (2012). 
"sentidos de humanidad", que dejaban "limpia la conciencia". Asesinan a la madre, "matan a quien deben matar" y "le evitan un hogar subversivo" al niño. En este sentido, otra ex detenidadesaparecida sobreviviente manifestó que la política de la Armada era que había que "salvar" a los chicos que nacían en el Centro Clandestino de Detención y "reeducarlos" en otras familias, que eran además "botines de guerra". Creía que este pensamiento correspondía al espíritu de la iglesia católica: "se salvaba al hijo sacrificando a la madre". ${ }^{17}$

Una embarazada sobreviviente testificó ${ }^{18}$ que el general jefe del I Cuerpo del Ejército entre 1976 y 1980, quien decidió su libertad, tuvo una entrevista con ella el día de su liberación y le preguntó cuáles eran sus planes para el futuro. Le preguntó si su familia sabía que estaba embarazada. Intentó persuadirla de que lo más conveniente sería que entregara a su hijo en el momento de nacer ya que habría familias de militares que podrían hacerse cargo de su crianza y ella podría rehacer su vida más fácilmente una vez en libertad. Uno de los represores la obligó a bautizar a su hijo, imponiéndose como padrino del niño. Todo, "en nombre de Dios y de la Patria". ¿Cuáles habrán sido las razones de esta "propuesta"? ¿Se asumía que la mujer estaría dispuesta a "abandonar" a su hijo? ¿Se trataría de evitar que el niño creciera en un "hogar subversivo" y buscara "venganza"? ¿Se pretenderían erigir a las "familias de militares" no sólo en "salvadores" de la mujer, perdonándole la vida - hecho por demás excepcional sino también de la criatura permitiéndole "rehacer su vida"? ¿Cuál fue el sentido del padrinazgo del recién nacido, pretender perpetuar la vigilancia, no sólo física de su madre, sino también ideológica del niño, al menos de manera ilusoria?

No hay que olvidar, sin embargo, que detrás de estas declaraciones de principios, las realidades han sido variadas. Un número indeterminado de niños/as y mujeres embarazadas fueron

\footnotetext{
${ }^{17}$ Testimonio de M. A. M. en la embajada argentina en España el 13/07/1998.

${ }^{18}$ Testimonio de E. A. en Ginebra el 20/01/1983 y en Paris, el 12/03/1984 en presencia del cónsul argentino y del Dr. Marshal Meyer.
} 
efectivamente torturado/as y asesinados/as, con lo cual este objetivo de "salvación" debe relativizarse. Así también, los grupos familiares formados por los/as apropiadores/as, no siempre constituyeron familias "decentes" o "bien constituidas" en el sentido tradicional-conservador aludido: no se trató siempre de matrimonios conyugales, ya que hubo mujeres solas, divorcios, "abandonos". Tampoco estos gozaban siempre de una posición económica y social acomodada, y se han presentado casos de vulnerabilidad socioeconómica. A la vez, se registraron situaciones de violencia, abuso psicofísico, incluso sexual y de "dudosa moralidad" (por ejemplo, un niño pequeño sin supervisión adulta a cargo de tareas domésticas y del cuidado de otros pequeños, bajo la guarda de una mujer que ejercía la prostitución).

\section{Conclusiones}

Ya encontramos en la moderna tradición iluminista del siglo XVIII la invención de la "buena o mala madre" en tanto matriz del cuerpo social, con las marcas patriarcales, paternalistas $y$ naturalistas que se verán en posteriores tradiciones de pensamiento.

En la Argentina de fines del siglo XIX y principios del siguiente, la politización de la maternidad como preocupación estatal estuvo marcada por el transformismo del eugenismo positivo inspirado en el darwinismo social. La modificación de los individuos orientada a la construcción y perfeccionamiento del "ser nacional", la "argentinidad", el "crisol de razas", se realizaría a partir del medio, la educación, y se transmitiría por herencia. En este sentido se promovía la selección de progenitores para evitar la "degeneración" encarnada por los opositores políticos. El higienismo social reforzaba la metáfora de la infección: debía atacarse la "delincuencia política" en tanto enfermedad psicomoral para evitar el contagio, la transmisión intergeneracional de los "males sociales" y así la "degeneración", promoviendo la salud social de la "raza". 
Puede observarse la confluencia de estas tradiciones en el neoconservadurismo católico familiarista hegemónico en los años '70 en la Argentina. La familia natural patriarcal es considerada esencial en términos morales. Los padres y fundamentalmente las madres, son los/as responsables por la formación en valores y reproducción ideológica de sus miembros y así culpables por lo tanto de todos los "males", incluso de la desaparición. Dado que la familia es considerada la "célula básica" de la Nación, para garantizar el orden social el Estado debe intervenir en las familias que se hallen "desnaturalizadas". La metáfora de la nación como familia se completa con la metáfora de la subversión como enfermedad: debe "salvarse" a la familia de la "infiltración subversiva", evitar el "contagio" de la "enfermedad moral", para restaurar "el orden natural", los valores del "ser nacional", y salvar así a la sociedad toda.

¿Cuál era el contenido concreto de la categoría de mujer "subversiva" en clave moral? ¿Cuáles eran los valores connotados negativamente? Más allá de la diversidad de rasgos que pueden atribuirse a esta construcción, muchas veces contradictorios dependiendo del agente que la defina, pueden resaltarse algunos elementos importantes en cuanto a su clasificación como "malas madres". Fundamentalmente a partir de la actividad políticomilitar de estas mujeres, llamadas "terroristas", "delincuentes subversivas", aparece el "abandono" del que son objeto sus hijos/as, el peligro al que se hallaban expuestos/as, producto incluso del "desamor" materno.

Tras la detención, desaparición o asesinato de sus padres, muchos niños no fueron entregados a sus familias, porque justamente esas familias desnaturalizadas que habían formado "subversivos" podrían hacer otro tanto con su descendencia, "educar" a los niños para la subversión, conformar nuevos "guerrilleros", que recuperaran el proyecto político de sus padres. Así, el objetivo era evitar que los niños se críen con "odio" hacia las FFAA y busquen "venganza" por la desaparición de sus padres. La solución planteada por algunos actores fue la ubicación de las criaturas en "familias bien constituidas" con el fin de 
"enderezarlos", "mejorar la raza". A la inversa, Abuelas de Plaza de Mayo, aparece como el "ambiente" destinado a revertir el proyecto de la apropiación, y formar nuevas "réplicas" de sus padres.

En suma, fue así que a partir de esta construcción de las "subversivas" como "malas madres", de las familias "desnaturalizadas", y de la necesidad de la "salvación" del niño y de la sociedad, el neoconservadurismo familiarista y militarista pretendió justificar la apropiación de los/as niños/as hijos/as de detenidos/as- desaparecidos/as.

\section{Referencias bibliograficas}

ACTIS, Munú et alii. Ese infierno. Conversaciones de cinco mujeres sobrevivientes de la ESMA. Buenos Aires, Ed. Sudamericana, 2001.

ÁlVAREZ, Victoria. El encierro en los campos de concentración. En: GIL LOZANO, F.; PITA, V.; INI, María G. (orgs.) Historia de las mujeres en la Argentina. Buenos Aires, Ed. Siglo XX, Taurus, 2000, Tomo II, pp.6788.

AmADO, Ana y DOMÍNGUEZ, Nora. Lazos de familia: herencias, cuerpos, ficciones. Buenos Aires, Ed. Paidós, 2004.

Beiguelman, Bernardo. Genética y ética. Revista Ciência e Cultura 42 (1), Rio de Janeiro, 1990, pp.61-69.

Bock, Gisela. Maternidad y políticas de género. Antinatalismo, maternidad y paternidad en el racismo nacionalsocialista. En: BocK, G. y THANE, P. (Eds.) Maternidad y políticas de género. Las mujeres en los Estados de Bienestar europeos, 1880-1950. Madrid, Ed. Cátedra, Universidad de Valencia, Instituto de la Mujer, 1996, pp. 401-437.

BOSWELL, John. The Kindness of Strangers - the abandonment of children in Western Europe from Late Antiquity to the Renaissance. New York, Ed.Vintage Books, 1988.

CAlveiro, Pilar. Poder y desaparición. Los campos de concentración en Argentina. Buenos Aires, Colihue, 1995. 
COSSE, Isabella. Estigmas de nacimiento. Peronismo y orden familiar (1946-1955). Buenos Aires, Ed. Fondo de Cultura Económica, 2006.

FILC, Judith. Entre el parentesco y la política. Familia y dictadura, 19761983. Buenos Aires, Ed. Biblos, 1997.

FONSECA, Claudia. Da circulação de crianças à adoção internacional. Cadernos Pagu (26), Campinas-SP, Núcleo de Estudos de GêneroPagu-Unicamp, 2006, pp.11-43.

FOUCAULT, Michel. La verdad y las formas jurídicas. Barcelona, Gedisa, 2003.

GRASSI, Estela. Redefinición del papel del Estado en la reproducción y cambios en el discurso sobre familia y mujer en Argentina. En: GONZÁLEZ MONTES, S. (coord.) Mujeres y relaciones de género en la antropología latinoamericana. México, Ed. El Colegio de México, 1993, pp.223-251.

GuY, Donna. The Shifting Meanings of Childhood and "N.N.". Latin American Perspectives, Sage Publications, 2008, pp.15-35.

HERZFELD, Michael. The social production of indiference: exploring the Symbolic Roots of Western Bureaucracy. Nueva York, Berg Publishers, 1992.

KNIBIEHLER, Yvonne. Historia de las madres y de la maternidad en occidente. Buenos Aires, Nueva Visión, 2001.

MonREAl ReQuenA, Pilar. Las madres no nacen, se hacen. Perspectivas desde la antropología social. En: FERNÁNDEZ-MONTRAVETA, C. et alii (Eds.) Las representaciones de la maternidad. Madrid, Instituto Universitario de la mujer, Universidad Autónoma de Madrid, 2000, pp.49-60.

MorenO, María. Dora Bovary (El imaginario sexual en la generación del 80). En: LuDMER, J. (comp.) Las culturas de fin de siglo en América Latina. Rosario, Beatriz Viterbo Editora, 1994, pp.115-138.

NARI, Marcela. Las Políticas de la maternidad y maternalismo político (Buenos Aires, 1890-1940). Buenos Aires, Biblos, 2005.

NosigliA, Julio. Botín de Guerra. Argentina, La Página, 1985. 
452 "Subversivas": "Malas madres" y familias "desnaturalizadas

OBerti, Alejandra. La moral según los revolucionarios. Política de la Memoria. Anuario de Investigación del CeDInCI, núm. 5, Buenos Aires, diciembre de 2004, pp.77-84.

PAlOMAR VereA, Cristina. "Malas madres": la construcción social de la maternidad. Debate feminista, año 15, vol. 30, octubre, Méjico, 2004, pp.12-25.

REGUEIRO, Sabina. Análisis genético para la identificación de niños apropiados: construcción política y científica de la "naturaleza" y el parentesco. Revista Estudos Feministas, vol. 18, nº 1 , Centro de Filosofia e Ciências Humanas Centro de Comunicação e Expressão, Universidade Federal de Santa Catarina, enero-abril 2010, pp.11-32.

SALABERRY, Mariela. Mariana, tú y nosotros. Montevideo, Ediciones de la Banda Oriental,1993.

SALESSI, Jorge. Médicos maleantes y maricas: higiene, criminología y homosexualidad en la construcción de la nación argentina (Buenos Aires, 1871-1914). Rosario, Beatriz Viterbo, 1995.

SANJURJO, Liliana. Sangue, identidade e verdade histórica: criancas desaparecidas e memorias sobre o passado ditatorial na Argentina. Soc. e Cult. Goiania, vol. 15, n², jul.2012, pp.427-438.

TUBERT, Silvia. Figuras de la madre. Madrid, Ed. Cátedra, Universitat de Valencia, Instituto de la mujer, 1996.

VezzetTI, Hugo. Pasado y presente. Guerra, dictadura y sociedad en la Argentina. Buenos Aires, Siglo XXI, 2002.

VIANNA, Adriana. Limites da Menoridade: tutela, família e autoridade em julgamento. Tese de Doutorado, Antropologia Social, Museu Nacional da Universidade Federal do Rio de Janeiro, 2002.

VillaltA, Carla. Entregas y secuestros. El rol del estado en la apropiación de niños. Buenos Aires, Editoriales del Puerto, CELS, 2012. 